"This document is the Accepted Manuscript version of a Published Work that appeared in final form in Chemistry of Materials, copyright (C) American Chemical Society after peer review and technical editing by the publisher. To access the final edited and published work see [insert ACS Articles on Request author-directed link to Published Work, see

\title{
In-situ Formation of Heterojunctions in Modified Graphitic Carbon Nitride: Synthesis and Noble Metal Free Photo-catalysis
}

\author{
Menny Shalom ${ }^{\dagger} *$, Miguel Guttentag ${ }^{1 \xi}$, Christian Fettkenhauer ${ }^{\dagger}$, Sahika Inal ${ }^{ \pm}$, Dieter Neher ${ }^{ \pm}$ \\ Antoni Llobet ${ }^{I}$, Markus Antonietti ${ }^{\dagger}$
}

${ }^{\dagger}$ Max-Planck Institute of Colloids and Interfaces, Department of Colloid Chemistry, Research Campus Golm, 14424 Potsdam, Germany

` Institut Català d'Investigació Química, Paisos Catalans 16, Tarragona, 43007, Spain

${ }^{ \pm}$Institute of Physics and Astronomy, University of Potsdam, Karl-Liebknecht-Str. 24-25, Potsdam, 14476, Germany

E-mail address: menny.shalom@ mpikg.mpg.de

Herein we report the facile synthesis of an efficient roll-like carbon nitride $\left(\mathrm{C}_{3} \mathrm{~N}_{4}\right)$ photocatalyst for hydrogen production using a supramolecular complex composed of cyanuric acid, melamine and barbituric acid as the starting monomers. Optical and photocatalytic investigations show, along with the known red shift of absorption into the visible region, that the insertion of barbituric acid results in the in situ formation of in-plane heterojuctions, which enhance the charge separation process under illumination. Moreover, platinum as the standard co-catalyst in photocatalysis could be successfully replaced with first row transition metal-salts and complexes under retention of $50 \%$ of the catalytic activity. Their mode of deposition and interaction with the semiconductor was studied in detail. Utilization of the supramolecular approach opens new opportunities to manipulate charge transfer process within carbon nitride toward the design of more efficient carbon nitride photocatalyst with controlled morphology and optical properties. 


\section{Introduction}

The production of solar fuels through water splitting is highly desired due to the increasing demands for clean and renewable energy. ${ }^{1}$ In general, the semiconductor photocatalyst should possess a suitable band gap $(<1.23 \mathrm{eV})$ with the right position of conduction and valence band. ${ }^{2}$ In addition, the photocatalytic performance is strongly dependent on the charge transfer processes of the semiconductor under illumination (electrons and holes separation and internal recombination rate). One of the ways to manipulate the charge separation of excitons in many light-driven reactions (e.g. in solar cells, ${ }^{3}$ light-emitting diodes $^{4}$ or for photocatalysis ${ }^{5}$ ) is the formation of a heterojunction which can be carefully designed in order to direct the charge flow in a given direction. While most of the research in this field was focused on metal-based semiconductors (metal oxides, ${ }^{6}$ sulfides $^{7}$ and nitrides ${ }^{8}$ ) as photocatalysts, in the last years metal-free graphitic carbon nitride $\left(\mathrm{C}_{3} \mathrm{~N}_{4}\right)$ materials have attracted widespread attention due to their outstanding (electro)catalytic and photocatalytic activity. ${ }^{9} \mathrm{C}_{3} \mathrm{~N}_{4}$ materials demonstrate high activity in many energy-related fields: as catalyst in heterogeneous catalysis and as metal-free photocatalysts and electrocatalysts in watersplitting reactions, ${ }^{10}, 11$ in the degradation of pollutants, ${ }^{12}$ and many more. The growing interest in $\mathrm{C}_{3} \mathrm{~N}_{4}$ materials as photo- and electro-catalyst is mainly due to its excellent chemical and photophysical properties. Apart of its high chemical and thermal stability (up to $400^{\circ} \mathrm{C}$ ), energy level positions of $\mathrm{C}_{3} \mathrm{~N}_{4}$ materials are suitable for water splitting under illumination (both proton reduction and water oxidation). The photocatalytic activity of $\mathrm{C}_{3} \mathrm{~N}_{4}$ is strongly dependent on its morphology, size, surface area, defects, and energy states along with its electronic properties (band gap, exciton lifetime etc.). In the last year, many modifications of the common synthesis were developed, including the introduction of new heteroatoms (sulfur, phosphor) ${ }^{13}$ into the $\mathrm{C}_{3} \mathrm{~N}_{4}$ structure, in order to manipulate its electronic, optical and catalytic properties. However, despite great progress in $\mathrm{C}_{3} \mathrm{~N}_{4}$ synthesis, the traditional solid-state synthesis of $\mathrm{C}_{3} \mathrm{~N}_{4}$ results in disorganized texture, with small grain size and surface defects, which leads to low catalytic activity. 
Recently, other groups and ours used the supramolecular chemistry approach to synthesize ordered structures of $\mathrm{C}_{3} \mathrm{~N}_{4}$ such as hollow boxes, spheres and spherical macroscopic assemblies. ${ }^{12,14}$ In addition, this approach can also be applied to grow $\mathrm{C}_{3} \mathrm{~N}_{4}$ on different substrates. ${ }^{10}$ Supramolecular chemistry provides a great opportunity for the synthesis of nanostructured materials without any further templating techniques. The supramolecular approach includes the use of non-covalent interactions such as hydrogen bonding to form order between building blocks for the desired synthesis. Hydrogen bonds are very useful for controlling molecular self-assembly thanks to the reversibility, specificity, and directionality of this class of interactions. ${ }^{15,16}$ The structure of the final products can be controlled by choosing the appropriate monomers and solvents for the synthesis. The starting monomers will organize in different structures according to their ability to form hydrogen bonds in the given solvent and form ordered and stable aggregates which consecutively define the resulting materials.

Here we use the supramolecular approach in order to improve the efficiency of the $C_{3} N_{4}$ photocatalyst for hydrogen evolution. The modified carbon nitride was prepared by the pyrolysis of the supramolecular complex of cyanuric acid (C), melamine (M), and barbituric acid (B) as precursors in different molar ratios. We demonstrate that changes in the hydrogen bond network and the replacement of nitrogen atoms with carbon strongly influenced the electronic and the chemical properties of $\mathrm{C}_{3} \mathrm{~N}_{4}$. Moreover, lifetime measurements indicated the in situ generation of heterojunctions, which are favorable for photocatalytic applications. The chemical structure, morphology and optical properties of the resulting carbon nitrides were characterized by X-ray diffraction (XRD), Fourier transformed infrared (FT-IR) spectroscopy, scanning electron microscopy (SEM), Elemental Analysis, UV-vis absorption, steady-state and time-resolved fluorescence spectroscopy. The photocatalytic activities of the different modified $\mathrm{C}_{3} \mathrm{~N}_{4}$ 's were tested by measuring hydrogen evolution in combination with Pt, first row transition metal salts and known water reduction catalysts as co-catalysts.

\section{Results and discussion}

Supramolecular $\mathrm{CM}_{1} \mathrm{~B}_{\mathrm{x}}$ complexes were prepared by mixing different molar ratio of the three precursors in water (equimolar amounts of melamine and cyanuric acid $=\mathrm{CM}_{1}, \mathrm{x}=0.0033$, $0.05,0.1,0.5$ molar ratio of barbituric acid with respect to $\left.\mathrm{CM}_{1} . \mathrm{CM}: \mathrm{B}=1: \mathrm{x}\right)$. Although the 
solubility of the three monomers in water is generally low, it was sufficient to allow for the formation of organized aggregates after $4 \mathrm{~h}$ of shaking (Figure S1). In the absence or in low amounts of barbituric acid $(<0.1)$ the formation of rod-like aggregates of CMB complex was observed, while in high amount the aggregates in water exhibited a disk-like structure. The change in morphology with higher barbituric acid concentration was probably due to the removal of one hydrogen bond structural unit (when comparing barbituric acid with cyanuric acid), which allowed for more flexibility during the supramolecular complex formation.

Evidence for the formation of high crystallinity supramolecular complexes is given by the FTIR spectroscopy and XRD analysis (Figure S2). ${ }^{16}$ The formation of hydrogen bonds was reflected in the FT-IR spectra by the shift of the stretching vibration of the $\mathrm{C}=0$ groups in the cyanuric and barbituric acid from 1691 to $1730 \mathrm{~cm}^{-1}$ and by the shift of the triazine ring vibration of melamine to lower wavenumbers (from 812 to $761 \mathrm{~cm}^{-1}$ ). In addition, the stretching vibration of the $\mathrm{N}-\mathrm{H}$ group in melamine disappeared. The appearance of new XRD peaks for $\mathrm{CMB}$ compared with the starting monomers is strong evidence for the creation of new arrangements (Figure S2b). The indication for an in-plane pattern in $\mathrm{CM}_{1} \mathrm{~B}_{\mathrm{x}}$ is shown by the well-resolved peaks at 10.7, 19.8 and $21.75^{\circ}$, which can be indexed as (100), (110) and (200) of the in-planar packing, respectively. Photoactive carbon nitride materials were obtained by heating the $\mathrm{CMB}$ complexes to $550{ }^{\circ} \mathrm{C}$ for 4 hours under nitrogen atmosphere with a heating ramp of $2.3 \mathrm{~K} / \mathrm{min}$. The effect of barbituric acid on texture is clearly observed in the SEM images of all $\mathrm{CM}_{1} \mathrm{~B}_{\mathrm{X}}-\mathrm{C}_{3} \mathrm{~N}_{4}$ samples (Figure 1). 


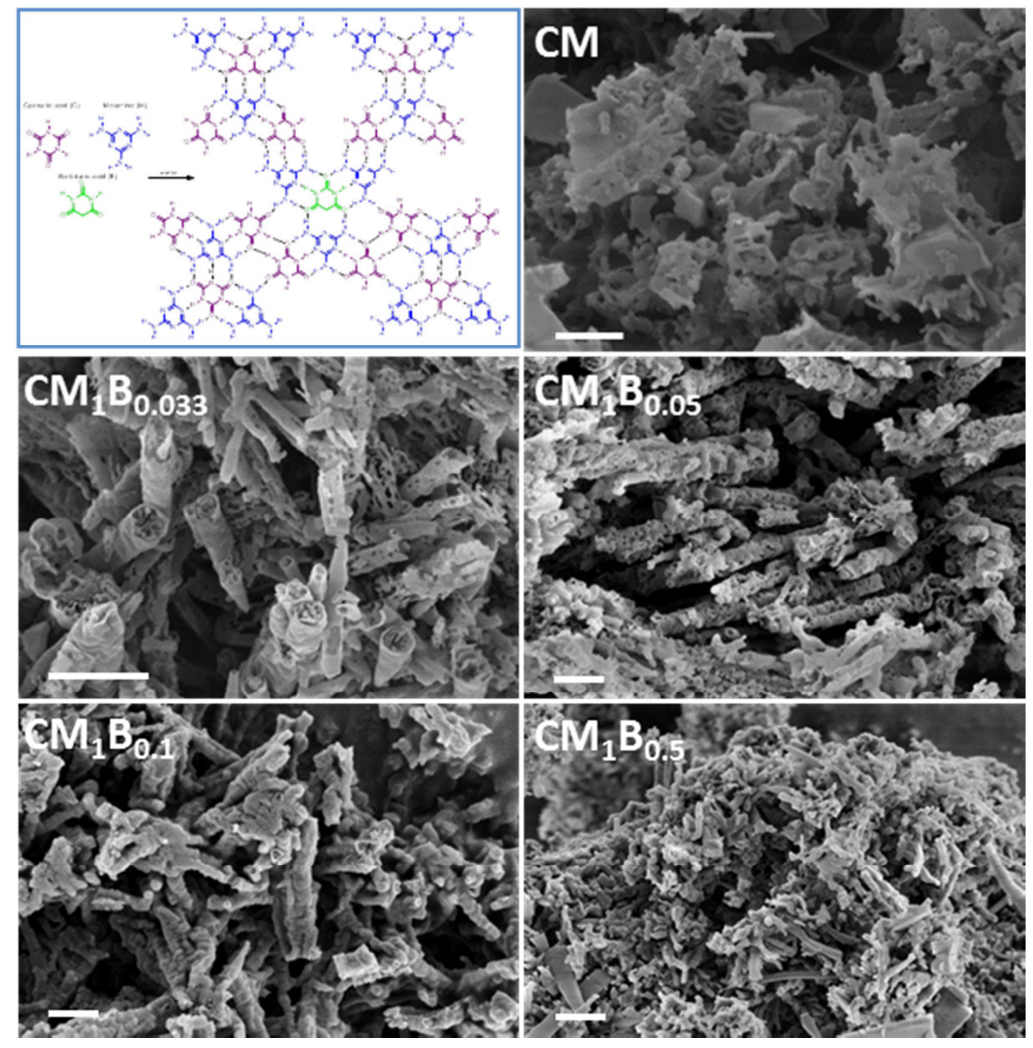

Figure 1. Graphic representation of the $\mathrm{CM}_{1} \mathrm{~B}_{\mathrm{x}}$ supramolecular complex (see also scheme $\mathrm{S} 1$ ) and SEM images of the hydrogen-bonded complexes $\mathrm{CM}_{1} \mathrm{~B}_{\mathrm{X}}-\mathrm{C}_{3} \mathrm{~N}_{4}$ in different molar ratios after condensation at $550{ }^{\circ} \mathrm{C}$ for 4 hours. Scale bars are $1 \mu \mathrm{M}$.

The morphology changed from sheet-like to a roll-like structure, even with low amounts of barbituric acid, due to the local removal of one hydrogen bond. We speculate that the removal of one hydrogen bond introduced more adaptability to the complex by adding more degrees of freedom, which resulted in the ability to create ordered 3D structures. At higher barbituric acid concentration in the starting complex, the roll-like morphology was partially destroyed, and a less regular nanostructured morphology was obtained. This change was also reflected by the BET surface area of all the $\mathrm{CM}_{1} \mathrm{~B}_{\mathrm{X}}-\mathrm{C}_{3} \mathrm{~N}_{4} \mathrm{~S}$ materials (Figure S3). In the absence and with a low amount of barbituric acid in the starting complex the surface area was relatively high $\left(60-70 \mathrm{~m}^{2} \mathrm{~g}^{-1}\right)$, while its further increase resulted in a surface area decrease. The formation of carbon nitride after heating was confirmed by FT-IR and XRD analyses (Figure 2). ${ }^{17}$ The vibrational spectra of the $\mathrm{CM}_{1} \mathrm{~B}_{\mathrm{x}}-\mathrm{C}_{3} \mathrm{~N}_{4}$ materials were compared to the one that condensed solely from dicyandiamide (DCDA). The strong stretching modes of $\mathrm{CN}$ heterocycles from 1200 to $1600 \mathrm{~cm}^{-1}$ alongside the characteristic breathing mode of the triazine units at $800 \mathrm{~cm}^{-1}$ were observed, confirming the formation of $\mathrm{C}_{3} \mathrm{~N}_{4}$. Additional proof for the $\mathrm{C}_{3} \mathrm{~N}_{4}$ formation is given by the XRD patterns (Figure $2 \mathrm{~b}$ ). The pattern of the carbon 
nitride which was condensed from $\mathrm{CM}_{1} \mathrm{~B}_{\mathrm{X}}$ is similar to the one which was prepared by DCDA condensation. The strong interplanar stacking peak of aromatic systems around $27.2^{\circ}$ (indexed as 002) was shifted to lower degrees and became less pronounced and broader with additional barbituric acid. The shift of the interplanar stacking peak can be explained by higher defect rate in the $\mathrm{CM}_{1} \mathrm{~B}_{\mathrm{x}}-\mathrm{C}_{3} \mathrm{~N}_{4} \mathrm{~S}$ and by the polymer-like growth of $\mathrm{CM}_{1} \mathrm{~B}_{\mathrm{x}}-\mathrm{C}_{3} \mathrm{~N}_{4}$ compared with the grain-growth in the DCDA route.
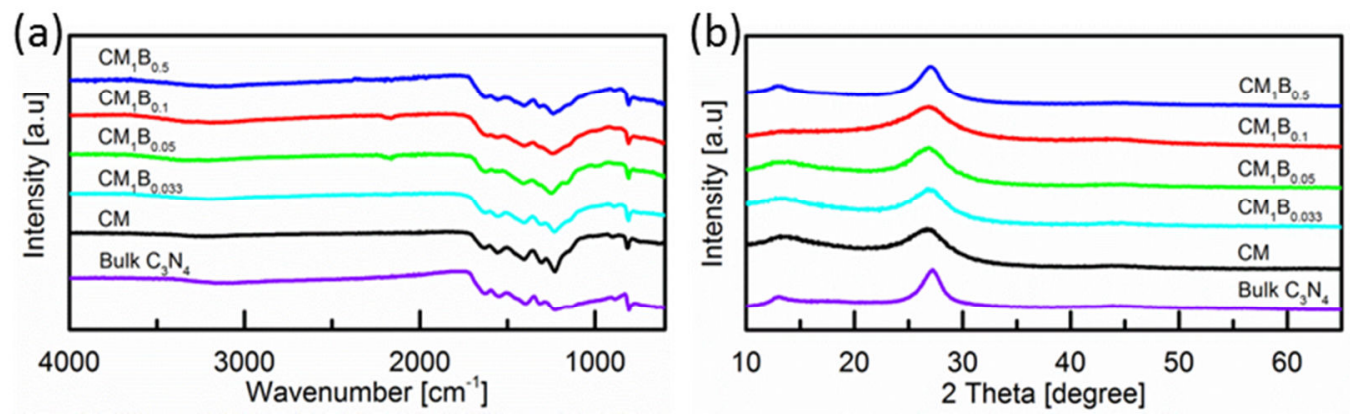

Figure 2. FT-IR spectra (a) and X-ray diffraction pattern (b) of $\mathrm{CM}_{1} \mathrm{~B}_{\mathrm{x}}$ after condensation at $550{ }^{\circ} \mathrm{C}$ for 4 hours, indicating the formation of $\mathrm{C}_{3} \mathrm{~N}_{4}$.

The formation of $\mathrm{C}_{3} \mathrm{~N}_{4}$-like materials was also confirmed by elemental analysis (Table S1). For all the $\mathrm{CM}_{1} \mathrm{~B}_{\mathrm{x}}-\mathrm{C}_{3} \mathrm{~N}_{4}$ materials, the $\mathrm{C} / \mathrm{N}$ molar ratio varied from 0.7-0.77 (the increase of carbon content was due to a larger amount of barbituric acid in the starting complex) with $\sim 2 \%$ hydrogen only, meaning that most of the $\mathrm{NH}_{2}$ groups reacted during the condensation process. In addition, the total weight of all the elements clearly indicated the absence of oxygen, implying that most if not all the oxygen from the $\mathrm{C}=\mathrm{O}$ groups in the cyanuric and barbituric acid were eliminated.

In order to evaluate the changes in the electronic properties of the modified $\mathrm{C}_{3} \mathrm{~N}_{4} \mathrm{~S}$, we measured their photophysical properties. In general, different morphologies, composition, surface states, and defect sites can directly influence the electronic properties of $C_{3} N_{4}$. The UV-vis diffuse reflectance absorbance spectra of all the $\mathrm{CM}_{1} \mathrm{~B}_{\mathrm{x}}-\mathrm{C}_{3} \mathrm{~N}_{4}$ materials are shown in Figure 3a. For all the modified $\mathrm{CM}_{1} \mathrm{~B}_{\mathrm{x}}-\mathrm{C}_{3} \mathrm{~N}_{4}$ materials, the absorption edges were red-shifted to lower energies along with an increase of optical densities at longer wavelengths. The red shift in absorption spectra indicates an alteration of the electronic band structure due to the replacement of nitrogen atoms by carbon atoms, as was previously described by Wang et $a l^{18}$. Further changes in the electronic properties are shown in the photoluminescence (PL) spectra of the $\mathrm{CM}_{1} \mathrm{~B}_{\mathrm{x}}-\mathrm{C}_{3} \mathrm{~N}_{4}$ (Figure $3 \mathrm{~b}$ ). As observed in the absorption spectra, the emission 
peak of all the $\mathrm{CM}_{1} \mathrm{~B}_{\mathrm{X}}-\mathrm{C}_{3} \mathrm{~N}_{4}$ materials shifted to lower energy compared to that of the $\mathrm{CM}$ $\mathrm{C}_{3} \mathrm{~N}_{4}$. In addition, the emission intensity is strongly quenched for almost all the $\mathrm{CM}_{1} \mathrm{~B}_{\mathrm{X}}-\mathrm{C}_{3} \mathrm{~N}_{4}$ materials, probably due to different charge transfer process as will be discussed later.
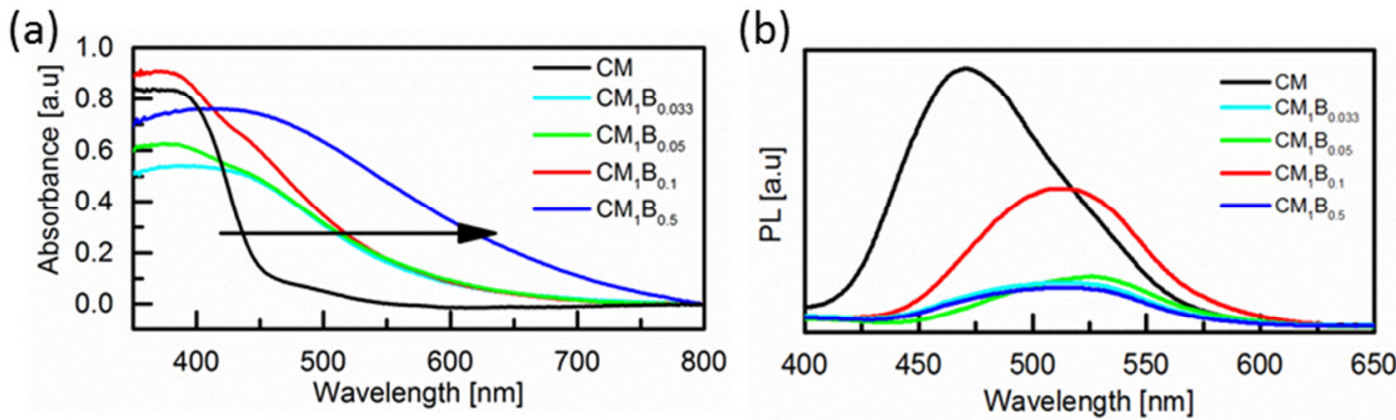

Figure 3. Diffuse reflectance absorption spectra (a) and emission spectra (b) of $C M_{1} B_{x}-C_{3} N_{4}$ obtained after condensation at $550^{\circ} \mathrm{C}$ for 4 hours.

In order to evaluate the photo-activity of the $\mathrm{CM}_{1} \mathrm{~B}_{\mathrm{x}}-\mathrm{C}_{3} \mathrm{~N}_{4}$ materials with respect to the bulk and porous $\mathrm{C}_{3} \mathrm{~N}_{4}$, we measured the hydrogen evolution in a water/triethanolamine (TEOA) solution and with $\mathrm{Pt}$ as co-catalyst under white light illumination. Considering the low abundance and high cost of platinum, we further conducted a detailed investigation of $\mathrm{CM}_{1} \mathrm{~B}_{0.05}$ in combination with different known molecular water reduction catalysts (WRCs) and a variety of first row transition metal salts as co-catalysts. In particular detail was investigated the interaction of $\mathrm{CM}_{1} \mathrm{~B}_{0.05}$ with $\mathrm{Co}\left(\mathrm{BF}_{4}\right)_{2}$ and the nature of the catalytic active species in this system.

All of the $\mathrm{CM}_{1} \mathrm{~B}_{\mathrm{x}}-\mathrm{C}_{3} \mathrm{~N}_{4}$ materials demonstrated higher catalytic activity with $\mathrm{Pt}$ as co-catalyst compared to the bulk and $\mathrm{CM}-\mathrm{C}_{3} \mathrm{~N}_{4}$. Moreover, the best photocatalyst $\left(\mathrm{CM}_{1} \mathrm{~B}_{0.05}\right)$ shows more than $60 \%$ higher turnover frequency (TOF) compared to mesoporous $\mathrm{C}_{3} \mathrm{~N}_{4}$, which is one of the most photo-active $\mathrm{C}_{3} \mathrm{~N}_{4}$ modifications reported up to date. In addition, the photocatalyst demonstrated high stability in the hydrogen evolution reaction, as shown in Figure S4 and S6. The enhanced photocatalytic activity can originate from several factors: (1) better light harvesting which can lead to more charge carriers that can be used in the catalytic process (2) improvement of the charge separation process (with appropriate energy band positioning), and (3) high surface area. From the absorption spectra and the hydrogen production rate it can be estimated that there is no direct correlation between the light harvesting and the photocatalytic activity (e.g. the hydrogen productions of $\mathrm{CM}_{1} \mathrm{~B}_{0.1} / 0.5$ are lower compared to $\mathrm{CM}_{1} \mathrm{~B}_{0.05} / 0.01$ although they absorb higher amount of light). In order to 
further study the charge separation process, we employed time-resolved fluorescence spectroscopy with a single photon counting set-up ${ }^{19}$. The intensity-averaged fluorescence lifetimes of all the $\mathrm{C}_{3} \mathrm{~N}_{4}$ materials are shown in Figure $4 \mathrm{~b}$. In accordance with the trend in the steady-state PL spectra, the fluorescence lifetime decreased for all the $\mathrm{CM}_{1} \mathrm{~B}_{x^{-}}-\mathrm{C}_{3} \mathrm{~N}_{4} \mathrm{~S}$ compared to $\mathrm{CM}$. The quenching of the emission intensity and its lifetime indicate that the relaxation of a fraction of $\mathrm{CM}_{1} \mathrm{~B}_{\mathrm{x}}-\mathrm{C}_{3} \mathrm{~N}_{4}$ excited states occurs via non-radiative paths, presumably through charge transfer of electrons and holes to new localized/surface states. Furthermore, for the most active materials, when the monitoring wavelength was changed from $475 \mathrm{~nm}$ to $525 \mathrm{~nm}$, the average fluorescence lifetime varied as well, which might point to the presence of more than one type of emitters. The variation of the lifetime suggests that at low barbituric acid concentration the $\mathrm{C}_{3} \mathrm{~N}_{4}$ materials was composed of a distribution of different semiconducting domains with different band gaps (probably due to the low amount of barbituric acid in the starting complex). The in situ creation of such domains can form heterojunctions at the grain boundaries, which facilitate the charge transfer processes and consequently enhance the photocatalytic activity (as illustrated in Figure S5).

(a)

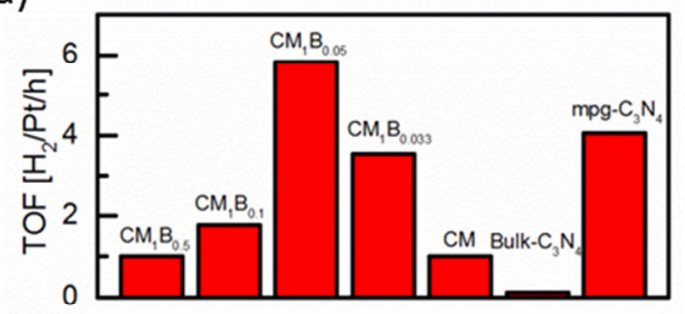

(c)

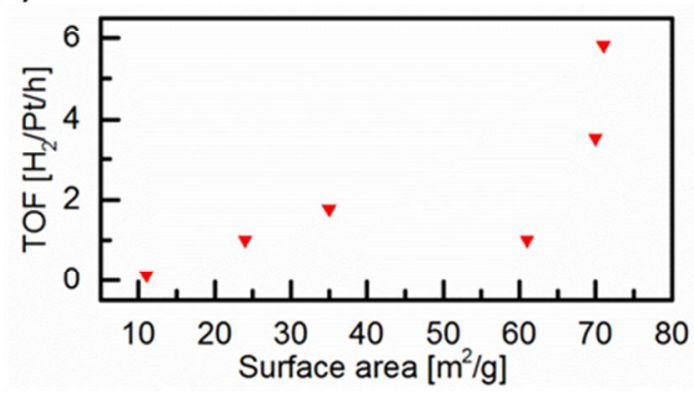

(b)

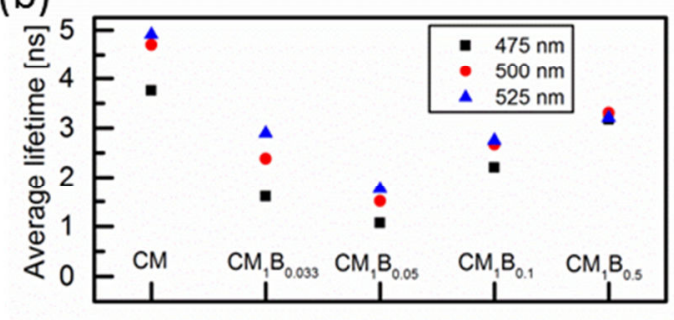

(d)

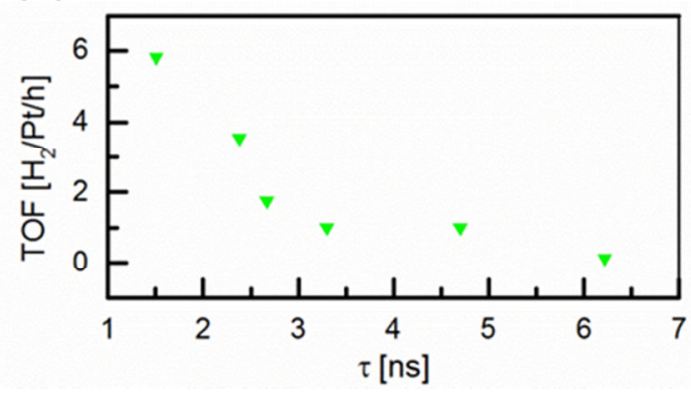

Figure 4. (a) TOFs for different $\mathrm{CM}_{1} B_{\mathrm{x}}-\mathrm{C}_{3} \mathrm{~N}_{4} \mathrm{~S}$, bulk- $\mathrm{C}_{3} \mathrm{~N}_{4}$ and mesoporous graphitic (mpg)- $\mathrm{C}_{3} \mathrm{~N}_{4}$ under photocatalytic conditions (50 mg g- $\mathrm{C}_{3} \mathrm{~N}_{4}, 0.21 \mathrm{mM} \mathrm{H}_{2} \mathrm{PtCl}_{6}, 10$ vol\% TEOA, $\mathrm{H}_{2} \mathrm{O}$, total volume $38 \mathrm{ml}$ ). (b) Intensity-averaged fluorescence lifetime of $\mathrm{CM}_{1} \mathrm{~B}_{\mathrm{x}}-\mathrm{C}_{3} \mathrm{~N}_{4} \mathrm{~s}$; the samples were excited at $405 \mathrm{~nm}$ and their emission was monitored at 475,500 and $525 \mathrm{~nm}$. $(c+d)$ TOF versus the surface area and TOF versus the average lifetime. Results are summarized in Table $\mathbf{S 2}$. 
In order to determinate whether the morphology or the electronic properties of the $\mathrm{CM}_{1} \mathrm{~B}_{\mathrm{X}}$ $\mathrm{C}_{3} \mathrm{~N}_{4}$ materials are responsible for the photo-activity, the hydrogen evolution rate was plotted as a function of the surface area and the fluorescence lifetime, respectively (Figure $4 \mathrm{c}$ and $4 \mathrm{~d}$ ). Although the surface area is related to the materials photo-activity, presumably due to the increase in number of active sites for the reaction, some of the $C_{1} B_{x}-C_{3} N_{4}$ materials exhibit different photo-activity for similar surface areas. Lifetimes, however, clearly correlate with the hydrogen evolution rate, suggesting that the photo-catalytic properties are mainly governed by the electronic structure. This further supports the theory of the formation of heterojunctions, since charge separated states were trapped more efficiently and therefore photocatalytic activity increased with decreasing life time.

In order to replace the platinum co-catalyst, a series of cobalt based WRCs and first row transition metals were tested with $\mathrm{CM}_{1} \mathrm{~B}_{0.05}$. In a typical standard experiment $3 \mathrm{~mL}$ of a degassed, aqueous solution of 10 vol\% TEOA, containing $4 \mathrm{mg} \mathrm{CM} \mathrm{CM}_{0.05}$ and $0.5 \mathrm{mM}$ of a metal salt or WRC were irradiated with 1 sun of visible light from a xenon lamp (> $400 \mathrm{~nm}$ cut off filter) and the evolving hydrogen was detected by means of a Clark electrode. Apart of TEOA other known sacrificial reducing agents were tested (namely ascorbic acid ${ }^{20}$, tris-(2carboxyethyl)phosphine/ascorbic $\operatorname{acid}^{21}$ and hydroquinone ${ }^{22}$ ), however, none of those systems produced hydrogen. Figure 5 a shows the hydrogen evolution traces for all active cocatalysts including the trace of a blank experiment, where a degased solution of only $\mathrm{CM}_{1} \mathrm{~B}_{0.05}$ and TEOA was irradiated. Turn over frequencies (TOFs), turnover numbers (TONs) and initialization-time (time between beginning of irradiation and start of $\mathrm{H}_{2}$ production) for all investigated co-catalysts are summarized in Table S3. While metal salts $\mathrm{Co}\left(\mathrm{BF}_{4}\right)_{2}, \mathrm{NiAc}_{2}$, and the complex $\left[\mathrm{CoDOH}\left(\mathrm{H}_{2} \mathrm{O}\right)_{2}\right]$TFMS$_{2}(\mathbf{S} 1)^{23}$ showed catalytic activity, CuTFMS $2, \mathrm{Fe}\left(\mathrm{SO}_{4}\right)_{2}$, $\mathrm{ZnCl}_{2}, \mathrm{AlTFMS}_{2},\left[\mathrm{Co}^{\mathrm{III}} \mathrm{CRCl}_{2}\right] \mathrm{Cl}(\mathbf{S 2})^{24}$ and $\left[\mathrm{Co}^{\prime \prime} \mathrm{TpyBr}_{2}\right](\mathbf{S 3})^{25}$ where inactive towards $\mathrm{H}_{2}$ production (Scheme S2). In the absence of a suitable co-catalyst the system did not produce any hydrogen. Complex S1 showed the highest initial rate with an initialization of 2.5 hours, while $\mathrm{Co}\left(\mathrm{BF}_{4}\right)_{2}$ performed less efficient but started $\mathrm{H}_{2}$ production already after 1 hour. $\mathrm{NiAc}_{2}$ was less active than both cobalt species, but started producing hydrogen almost instantaneously after beginning of irradiation. This stands in contrast to a report of Sun et al. When using traditional g- $\mathrm{C}_{3} \mathrm{~N}_{4}$ with Acriflavine as co-photo-sensitizer, nickel salts performed better than their cobalt analogues. ${ }^{26}$ The rather surprising complete inactivity of the two well-known WRCs $\mathbf{S} \mathbf{2}^{24}$ and $\mathbf{S} 3^{25}$ gave a first indication on the mode of interaction between 
$\mathrm{CM}_{1} \mathrm{~B}_{0.05}$ and its co-catalysts (vide infra). Although reduction by the semiconductor should be thermodynamically feasible, neither of the two catalysts produced hydrogen.
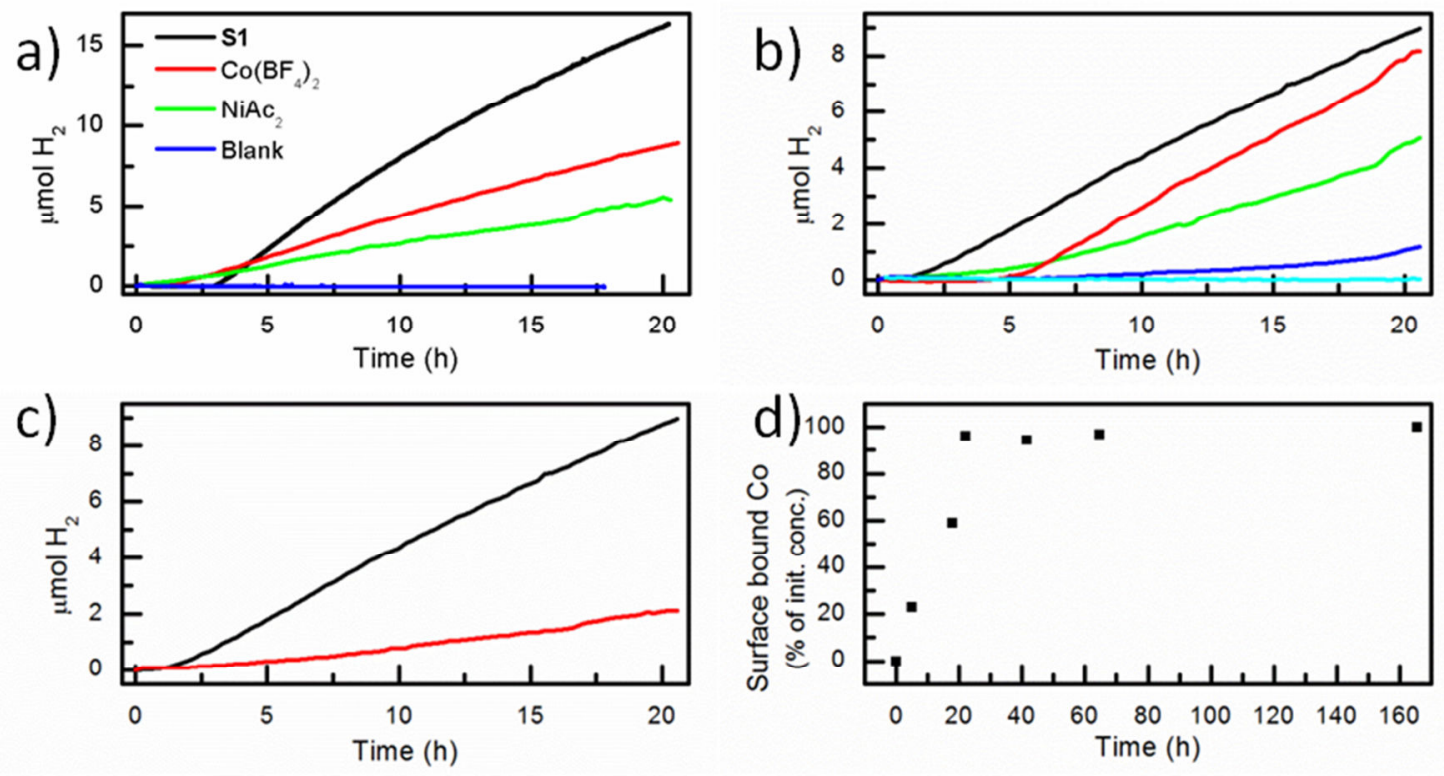

Figure 5. (a) $\mathrm{H}_{2}$ evolution traces for photo-catalytic experiments with different co-catalysts under standard conditions (4 mg CM $\mathrm{CM}_{0.05}, 0.5 \mathrm{mM}$ metal salt/ WRC, 10 vol\% TEOA, $\mathrm{H}_{2} \mathrm{O}$, total volume $3 \mathrm{~mL}$.) and blank experiment without co-catalyst. (b) $\mathrm{H}_{2}$ evolution traces for recycle experiments with $\mathrm{Co}\left(\mathrm{BF}_{4}\right)_{2}$. Black: typical first run under standard conditions (corresponds to red curve in figure $5 \mathrm{a}$ ). Green: recycled $\mathrm{CM}_{1} \mathrm{~B}_{0.05}$ from first run with fresh TEOA solution (10 vol\%). Red: recycled $\mathrm{CM}_{1} \mathrm{~B}_{0.05}$ from first run with fresh TEOA solution (10 vol\%) and additional $\mathrm{Co}\left(\mathrm{BF}_{4}\right)_{2}(0.5 \mathrm{mM})$. Blue: reuse of the solution from first run after 21 hours of irradiation with fresh $\mathrm{CM}_{1} \mathrm{~B}_{0.05}(4 \mathrm{mg})$. Cyan: reuse of the solution from first run after 70 hours of irradiation with fresh $\mathrm{CM}_{1} \mathrm{~B}_{0.05}(4$ mg). (c) Red: $\mathrm{H}_{2}$ evolution trace for recycled $\mathrm{CM}_{1} \mathrm{~B}_{0.05}$ with fresh TEOA solution (10 vol\%) after first run was performed in the dark. Black: standard experiment for comparison (corresponds to red curve in figure 5a). (d) Amount of surface bound cobalt, in percentage of initial concentration $(0.5 \mathrm{mM})$, for catalytic experiments under standard conditions stopped after different irradiation times.

In order to understand the nature of the catalytically active species when using $\mathrm{Co}\left(\mathrm{BF}_{4}\right)_{2}$ as a co-catalyst, a series of experiments were performed, in which either the solution or the solids where reused for a second photo-catalytic experiment (Figure 5b/c). At first, a catalytic standard solution was centrifuged after one day of irradiation, and the solid was washed and dried. Then, upon addition to a fresh solution of 10 vol\% TEOA only, catalytic activity was restored to about $50 \%$ of the original initial rate (Fig. $5 b$, green). When repeating the procedure, full catalytic activity could be restored when adding additional $\mathrm{Co}\left(\mathrm{BF}_{4}\right)_{2}$ to the second run (Fig. $5 \mathrm{~b}$, red). When filtering the catalytic solution after one day of irradiation and reusing the filtrate with fresh $\mathrm{CM}_{1} \mathrm{~B}_{0.05}$, catalytic activity was only restored 
to a very small extent (Fig. 5b, dark blue). These results strongly indicate a surface bound catalytically active cobalt species. This was further underlined by an experiment, where the first cycle was performed in the dark ( 1 night, no $\mathrm{H}_{2}$ detected). After separation from the first catalytic solution and subsequent washing and drying, the solid was used with a fresh solution of TEOA. The material still showed catalytic activity, suggesting the deposition or incorporation of cobalt into the semiconductor even in the absence of photo-induced reducing equivalents (Figure $5 c$, red).

Since reproducibility of the second runs were in all cases very dependent on the duration of the first run, a sequence of standard experiments were stopped at different reaction times, and the cobalt concentrations of the filtered solutions were determined by ICP measurements. The differences between the initial cobalt concentration and the results from the ICP quantification were assumed to be the amount of metal deposited in some manner on the surface (Figure $5 \mathrm{~d}$ ). Until about 25 hours after start of the reaction, surface cobalt concentration steadily increased up to the point, where all cobalt was bound to the semiconductor. This explained the low but still detectable activity in the second run of the recycle experiment, when fresh $\mathrm{CM}_{1} \mathrm{~B}_{0.05}$ was added to the filtered catalytic solution, and the not fully restored activity of the recycled $\mathrm{CM}_{1} \mathrm{~B}_{0.05}$ sample, since in both experiments the catalysis was stopped shortly before reaching complete deposition of the cobalt (small amount of cobalt were still in solution). Therefore, when the first cycle was stopped after 70 hours of irradiation (to ensure complete deposition of the metal) and then reusing the solution with a fresh sample of $\mathrm{CM}_{1} \mathrm{~B}_{0.05}$, no hydrogen was detected in 1 day of irradiation (Fig. 5b, light blue).

For the other metal salts investigated, the amount of deposited material was determined in the same manner with which the surface cobalt content was established. With the exception of AITFMS 2 , all metal ions were deposited on the surface of the semiconductor or somehow incorporated into its framework. The $\mathrm{Zn}$-salt and the $\mathrm{Cu}$-salt almost completely disappeared from the solution, the iron-salt to about $18 \%$. Nickel was deposited to around $28 \%$ after one day of catalysis. Similar to $\mathrm{Co}\left(\mathrm{BF}_{4}\right)_{2}$, it is probably gradually accumulated on $\mathrm{CM}_{1} \mathrm{~B}_{0.05}$. The same applies for S1, which showed around 32 \% less cobalt in solution after the same irradiation period (Table S3). The fact that the two highly stable WRCs S2 and S3 were inactive towards catalysis, strongly suggests, that mostly deposited material is acting as 
active species and that a significant portion of the activity of $\mathbf{S 1}$ is due to its deposited decomposition products undergoing a similar fate as $\mathrm{Co}\left(\mathrm{BF}_{4}\right)_{2}$. However, considering the high activity of S1 and reports of conventional g- $\mathrm{C}_{3} \mathrm{~N}_{4}$ used with similar WRCs the possibility of a homogeneous catalytic contribution cannot be discarded completely. ${ }^{27,} 28$

To further corroborate the presence of cobalt in the solids and as well to determine the nature of the deposition (either in form of nanoparticles or isolated, into the framework of the semiconductor incorporated cobalt ions), SEM-EDX and TEM experiments were performed with the solids before and after catalysis (Figure 6). Although cobalt was found by EDX analysis in the samples from after the catalysis (up to 0.2 mol\%, roughly consistent with ICP data), it was not possible to pinpoint the location of the metal. Distribution maps showed evenly dispersed cobalt over the whole of several of the investigated areas. In samples of fresh $\mathrm{CM}_{1} \mathrm{~B}_{0.05}$ no cobalt was detected. In agreement with the lack of discrete cobalt sites on the surface, no large agglomerates $(>5 \mathrm{~nm})$ of particles could be found in TEM analysis either, suggesting a mono-atomic distribution of cobalt on or in the semiconductor. In addition, the absence of crystalline cobalt aggregates is also evidenced in the XRD analysis (Figure S7) in which only the typical reflection peaks of $C_{3} N_{4}$ are obtained. ${ }^{12,29,30}$
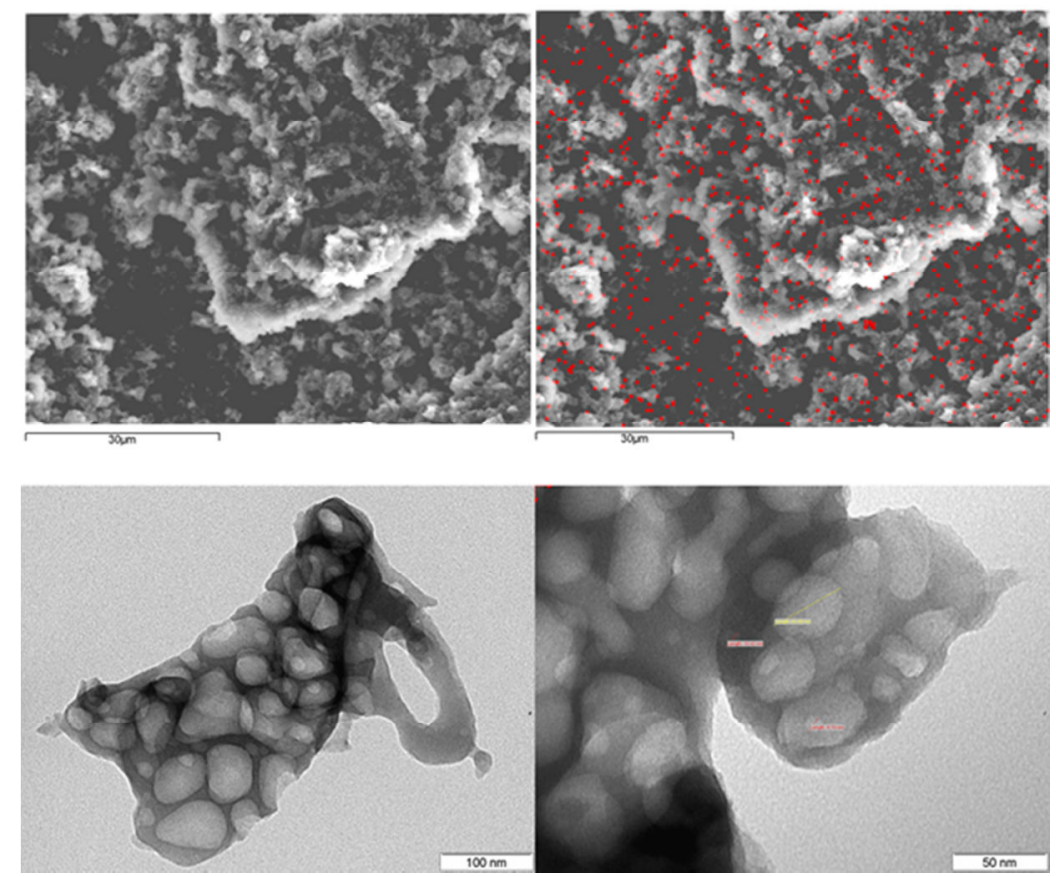

Figure 6. Top: SEM picture of $\mathrm{CM}_{1} \mathrm{~B}_{0.05}$ after catalysis (left, scale bar $30 \mu \mathrm{m}$ ) and mapping of cobalt according to EDX (right, scale bar $30 \mu \mathrm{m}$ ). Bottom: TEM pictures of $\mathrm{CM}_{1} \mathrm{~B}_{0.05}$ before (left, scale bar $100 \mathrm{~nm}$ ) and after (right, scale bar $10 \mathrm{~nm}$ ) catalysis. 


\section{Conclusions}

In summary, we demonstrate the synthesis of a highly efficient carbon nitride photocatalyst for hydrogen production by careful design of supramolecular complexes. The resulting $\mathrm{CM}_{1} \mathrm{~B}_{\mathrm{x}}-\mathrm{C}_{3} \mathrm{~N}_{4}$ demonstrates roll-like morphology with different chemical properties. In addition, the insertion of barbituric acid leads to an increase in the optical density along with a red shift into the visible region. The in situ formation of heterojunctions (composed from different semiconducting domains) is indirectly evident by life time measurements. The formation of heterojunction improves the charge separation process, resulting in high photocatalytic activity at low barbituric acid concentration. In addition, we also show the successful replacement of platinum as co-catalyst in photo-catalytic hydrogen production by more sustainable transition metals. The system is visible light responsive and performs well without an additional photo-sensitizer or use of UV-light. Co- and Ni-ions and complex S1 act as co-catalysts for $\mathrm{CM}_{1} \mathrm{~B}_{0.05}$ for photo-catalytic hydrogen generation. S1 shows the highest initial rate while $\mathrm{Co}\left(\mathrm{BF}_{4}\right)_{2}$ performed better than $\mathrm{NiAc}_{2}$. Recycle experiments and ICPmeasurements with $\mathrm{Co}\left(\mathrm{BF}_{4}\right)_{2}$ and $\mathrm{CM}_{1} \mathrm{~B}_{0.05}$ suggest a deposited catalytically active species rather than a homogeneous catalyst. SEM-EDX, TEM and XRD analysis show no evidence for particle formation above $5 \mathrm{~nm}$ diameter, further suggesting very small aggregates or a molecular catalytically active species. This work opens the possibility for facile synthetic modification and optimization of $\mathrm{C}_{3} \mathrm{~N}_{4}$ type semiconductors and semiconductor heteroassemblies, using only earth abundant and low cost starting materials. In addition, the substitution of platinum as co-catalyst with first row transition metals corroborates the importance of the further study of these systems. Lowering the absorption edge further into the visible and improving the interaction between heterogeneous co-catalysts and the material should allow for progressive improvement of photocatalytic efficiencies.

Supporting Information: Experimental details, SEM images, Nitrogen sorption isotherms, $\mathrm{FTIR}, \mathrm{XRD}$ and Elemental analysis data along with the structure of the catalysts investigated in this study are given in the supporting information.

\section{AUTHOR INFORMATION}




\section{Corresponding Author}

Menny.Shalom@mpikg.mpg.de

\section{Author Contributions}

${ }^{\S}$ These authors contributed equally to this work.

\section{Notes}

The authors declare no competing financial interest.

\section{ACKNOWLEDGMENTS}

M.S. would like to thank "Minerva Fellowship" for financial support. M.G. is grateful for a post-doctoral grant from the Swiss National Foundation. A.L. thanks MINECO (CTQ-201349075-R) and "La Caixa Foundation" for financial support. 


\section{REFERENCES}

1. H. B. Gray, Abstr. Pap. Am. Chem. Soc., 2013, 246, 1.

2. K. Maeda and K. Domen, J. Phys. Chem. Lett., 2010, 1, 2655-2661.

3. M. C. Scharber, D. Wuhlbacher, M. Koppe, P. Denk, C. Waldauf, A. J. Heeger and C. L. Brabec, Adv. Mater., 2006, 18, 789-+.

4. R. Konenkamp, R. C. Word and M. Godinez, Nano Lett., 2005, 5, 2005-2008.

5. H. Xu, Y. G. Xu, H. M. Li, J. X. Xia, J. Xiong, S. Yin, C. J. Huang and H. L. Wan, Dalton T., 2012, 41, 3387-3394.

6. M. Batzill, Energy Environ. Sci., 2011, 4, 3275-3286.

7. H. J. Yan, J. H. Yang, G. J. Ma, G. P. Wu, X. Zong, Z. B. Lei, J. Y. Shi and C. Li, J. Catal., 2009, 266, 165-168.

8. A. Kudo and Y. Miseki, Chem. Soc. Rev., 2009, 38, 253-278.

9. X. C. Wang, K. Maeda, A. Thomas, K. Takanabe, G. Xin, J. M. Carlsson, K. Domen and M. Antonietti, Nat. Mater., 2009, 8, 76-80.

10. M. Shalom, S. Gimenez, F. Schipper, I. Herraiz-Cardona, J. Bisquert and M. Antonietti, Angew. Chem.-Int. Edit., 2014, 53, 3654-3658.

11. Y. Zheng, Y. Jiao, J. Chen, J. Liu, J. Liang, A. Du, W. M. Zhang, Z. H. Zhu, S. C. Smith, M. Jaroniec, G. Q. Lu and S. Z. Qiao, J. Am. Chem. Soc., 2011, 133, 20116-20119.

12. M. Shalom, S. Inal, C. Fettkenhauer, D. Neher and M. Antonietti, J. Am. Chem. Soc., 2013, 135, 7118-7121.

13. Y. J. Zhang, T. Mori, J. H. Ye and M. Antonietti, J. Am. Chem. Soc., 2010, 132, 6294-+.

14. J. Young-Si, L. Eun Zoo, W. Xinchen, H. Won Hi, G. D. Stucky and A. Thomas, Adv. Funct. Mater., 2013, 23, 3661-3667.

15. T. Aida, E. W. Meijer and S. I. Stupp, Science, 2012, 335, 813-817.

16. G. Arrachart, C. Carcel, P. Trens, J. J. E. Moreau and M. W. C. Man, Chem.-Eur. J., 2009, 15, 6279-6288.

17. B. Jurgens, E. Irran, J. Senker, P. Kroll, H. Muller and W. Schnick, J. Am. Chem. Soc., 2003, 125, 10288-10300.

18. J. S. Zhang, X. F. Chen, K. Takanabe, K. Maeda, K. Domen, J. D. Epping, X. Z. Fu, M. Antonietti and X. C. Wang, Angew. Chem.-Int. Edit., 2010, 49, 441-444.

19. J. R. Lakowica, Springer, 2009, 3rd ed

20. M. Guttentag, A. Rodenberg, R. Kopelent, B. Probst, C. Buchwalder, M. Brandstätter, P. Hamm and R. Alberto, Eur. J. Inorg. Chem., 2012, 59-64.

21. C. Bachmann, B. Probst, M. Guttentag and R. Alberto, Chem. Commun., 2014, 50, 6737-6739.

22. B. Rausch, M. D. Symes and L. Cronin, J. Am. Chem. Soc., 2013, 135, 13656-13659.

23. B. Probst, M. Guttentag, A. Rodenberg, P. Hamm and R. Alberto, Inorg. Chem., 2011, 50, 3404-3412.

24. S. Varma, C. E. Castillo, T. Stoll, J. Fortage, A. G. Blackman, F. Molton, A. Deronzier and M. N. Collomb, Phys. Chem. Chem. Phys., 2013, 15, 17544-17552.

25. M. Guttentag, A. Rodenberg, C. Bachmann, A. Senn, P. Hamm and R. Alberto, Dalton T., 2013, 42, 334-337.

26. J. F. Dong, M. Wang, X. Q. Li, L. Chen, Y. He and L. C. Sun, ChemSusChem, 2012, 5, 2133-2138.

27. S. W. Cao, X. F. Liu, Y. P. Yuan, Z. Y. Zhang, J. Fang, S. C. J. Loo, J. Barber, T. C. Sum and C. Xue, Phys. Chem. Chem. Phys., 2013, 15, 18363-18366.

28. L. X., A. J. Ward, A. F. Masters and T. Maschmeyer, Chem. Eur. J., 2014, 20, 1-7.

29. J. S. Zhang, M. Grzelczak, Y. D. Hou, K. Maeda, K. Domen, X. Z. Fu, M. Antonietti and X. C. Wang, Chem. Sci., 2012, 3, 443-446.

30. J. T. Jin, X. G. Fu, Q. Liu and J. Y. Zhang, J. Mater. Chem., 2013, 1, 10538-10545. 